\title{
Penerapan Model Pembelajaran Problem Based Learning untuk Meningkatkan Hasil Belajar IPA Materi Gaya Kelas IV
}

\author{
Icha Larasati \\ Universitas Sebelas Maret \\ Ichalarasati16@gmail.com
}

\section{Article History}

received 30/4/2021

revised 30/5/2021

accepted 30/6/2021

\begin{abstract}
The learning process can affect student learning outcomes. Therefore, in the learning process, it is necessary to use an innovative learning model. The purpose of this study is to improve science learning outcomes in grade IV through the application of the PBL learning model. This research is a classroom action research conducted in two cycles. The subjects of this study were grade IV B students at SDN Dukuhan Kerten. Data collection techniques used tests, observations, and interviews. The results of the research in the first cycle showed that $78 \%$ of students completed. In the second cycle, it showed that $90 \%$ of students completed. These results indicate that the Problem Based Learning (PBL) learning model can improve student learning outcomes, especially Mupel Science Class IV at SDN Dukuhan Kerten Surakarta. . Therefore, this research is very important to be recommended to classroom teachers as an effort to improve the quality of the follow-up learning process and results that can be done.
\end{abstract}

Keywords: PBL, learning outcomes, science

\begin{abstract}
Abstrak
Proses pembelajaran dapat mempengaruhi hasil belajar siswa. Oleh karena itu dalam proses pembelajaran perlu adanya penggunaan model pembelajaran yang inovatif. Tujuan penelitian ini yaitu meningkatkan hasil belajar IPA di kelas IV melalui penerapan model pembelajaran PBL. Penelitian ini merupakan penelitian tindakan kelas yang dilaksanakan dalam dua siklus. Subjek penelitian ini adalah siswa kelas IV B di SDN Dukuhan Kerten. Teknik pengumpulan data menggunakan tes, observasi, dan wawancara. Hasil penelitian pada siklus I menunjukkan siswa yang tuntas sebesar $78 \%$. Pada siklus II menunjukkan siswa yang tuntas sebesar $90 \%$. Hasil ini menunjukan bahwa model pembelajaran Problem Based Learning (PBL) dapat meningkatkan hasil belajar siswa khususnya mupel IPA Kelas IV di SDN Dukuhan Kerten Surakarta. . Oleh karena itu, penelitian ini sangat penting untuk direkomendasikan kepada guru kelas sebagai upaya meningkatkan kualitas proses dan hasil pembelajaran tindak lanjut yang dapat dilakukan.
\end{abstract}

Kata kunci: $P B L$, hasil belajar, IPA 


\section{PENDAHULUAN}

IPA adalah mata pelajaran yang mengkaji fenoma-fenomena alam. Wisudawati dan Sulistiyowati (2017: 23) menjelaskan bahwa IPA berarti ilmu yang mempelajari tentang sebab dan akibat kejadian- kejadian yang ada di alam. Pada proses belajar IPA, siswa dituntut untuk dapat menemukan dan membangun pengetahuan secara mandiri sehingga pengetahuan yang siswa miliki lebih bermakna.

Namun pada kenyataannya siswa belum mampu membangun pengetahuannya secara mandiri yang mengakibatkan kurang maksimalnya hasil belajar IPA. Berdasarkan hasil temuan penulis di SDN Dukuhan Kerten, permasalahan yang muncul adalah hasil belajar siswa pada mata pelajaran IPA masih rendah. Hal ini didukung oleh nilai ulangan IPA tema 6 dan 7 dimana masih ada 11 siswa yang nilainya di bawah KKM dengan nilai standar KKM tuntas belajar 56\%. Berdasarkan permasalahan tersebut peneliti mengamati bahwa rendahnya hasil belajar mata pelajaran IPA dikarenakan siswa kurang fokus dalam memperhatikan penjelasan dari guru. Selain itu pada saat proses pembelajaran siswa kurang berperan aktif karena proses pembelajaran bersifat teacher center.

Melihat permasalahan di atas, maka dibutuhkan adanya perbaikan dalam pembelajaran IPA agar tujuan pembelajaran IPA di kelas dapat tercapai secara maksimal. Upaya perbaikan proses pembelajaran adalah dengan membangun suasana belajar yang bermakna, guru perlu menerapkan model pembelajaran yang inovatif dan menyenangkan yang dapat memfasilitasi siswa untuk membangun pengetahuannya secara mandiri.

Salah satu model pembelajaran yang inovatif dan mengaktifkan siswa serta melatih siswa untuk meningkatkan kemampuan pemecahan masalah yaitu model Problem Based Learning (PBL). Menurut Sani (2015: 127) Problem Based Learning (PBL) merupakan pembelajaran yang penyampainnya dilakukan dengan cara menyajikan suatu permasalahan, mengujikan pertanyaan-pertanyaan, memfasilitasi penyelidikan, dan membuka dialog. Pembelajaran berbasis masalah atau Problem Based Learning (PBL) adalah pendekatan pembelajaran menggunakan masalah autentik sebagai sumber belajar sehingga siswa dilatih berpikir tingkat tinggi dan mengembangkan kepribadian melalui masalah dalam kehidupan sehari-hari (Uno dan Mohammad, 2015: 112).

Penerapan model pembelajaran $\mathrm{PBL}$ pada penelitian ini berfokus pada pembelajaran IPA materi gaya kelas IV yang diharapkan dapat meningkatakan hasil belajar siswa kelas IV SDN Dukuhan Kerten Surakarta. Penerapan model PBL pada pembelajaran IPA untuk meningkatkan hasil belajar siswa telah dibuktikan keberhasilannya melalui penelitian sebelumnya. Hal ini dijelaskan dalam penelitian Nuraini dan Kristin (2017:11) yang menyatakan bahwa model Problem Based Learning dapat meningkatkan hasil belajar IPA. Hal ini diperkuat dengan penelitian Jayanti (2019:101) yang menyatakan bahwa model pembelajaran Problem Based Learning (PBL) dapat meningkatkan hasil belajar IPA materi gaya.

Berdasarkan uraian di atas maka rumusan masalah dalam penelitian ini, yaitu: (1) Bagaimanakah proses penerapan model Problem Based Learning (PBL) dalam meningkatkan hasil belajar IPA tentang gaya pada siswa kelas IV SD Negeri Dukuhan Kerten tahun ajaran 2020/2021; (2) apakah penerapan model pembelajaran Problem Based Learning (PBL) dapat meningkatkan hasil belajar siswa kelas IV SDN Dukuhan Kerten Tahun Pelajaran 2020/2021; (3) apakah kendala dan solusi penerapan model pembelajaran Problem Based Learning (PBL) dalam meningkatkan hasil belajar siswa kelas IV SDN Dukuhan Kerten Tahun Pelajaran 2020/2021.

Tujuan penelitian ini yaitu: (1) mendeskripsikan langkah-langkah penerapan model pembelajaran Problem Based Learning (PBL) dalam peningkatan hasil belajar IPA tentang gaya pada siswa kelas IV SDN Dukuhan Kerten tahun ajaran 2020/2021; (2) meningkatkan hasil belajar IPA materi gaya pada siswa kelas IV SDN Dukuhan Kerten 
tahun ajaran 2020/2021 melalui peerapan model pembelajaran Problem Based Learning (PBL); (3) mendeskripsikan kendala dan solusi penerapan model pembelajaran Problem Based Learning (PBL) dalam peningkatan hasil belajar IPA tentang gaya pada siswa kelas IV SDN Dukuhan Kerten tahun ajaran 2020/2021.

\section{METODE}

Penelitian ini adalah penelitian tindakan kelas. Adapun subjek penelitian ini adalah guru dan siswa kelas IV B SDN Dukuhan Kerten yang berjumlah 25 siswa. Penelitian ini dilaksanakan selama dua siklus secara daring menggunakan zoom meeting yang dilaksanakan dua pertemuan disetiap siklusnya. Siklus I dilaksanakan pada tanggal 16 Maret dan 17 Maret 2021. Siklus II dilaksanakan pada tanggal 24 Maret dan 25 Maret 2021. Jenis data pada penelitian ini adalah data kualitatif berupa penerapan model pembelajaran PBL dan data kuantitatif berupa hasil tes siswa dalam muatan pelajaran IPA. Sumber data dalam penelitian ini yaitu guru dan siswa. Teknik pengumpulan data menggunakan observasi, wawancara, dan tes dengan google formulir. Uji validitas data pada penelitian ini menggunakan triangulasi teknik dan triangulasi sumber. Analisis data penelitian meliputi kegiatan reduksi data, penyajian data, dan penarikan kesimpulan.

Indikator kinerja penelitian ini adalah peningkatan pembelajaran siswa dalam mata pelajaran IPA dengan ketercapaian target $85 \%$. Penelitian ini menggunakan prosedur penelitian Kemmis dan Taggart (Arikunto, 2013: 137), yaitu terdiri dari tahap perencanaan, pelaksanaan, pengamatan, dan refleksi yang secara rinci disajikan dalam bagan berikut ini.

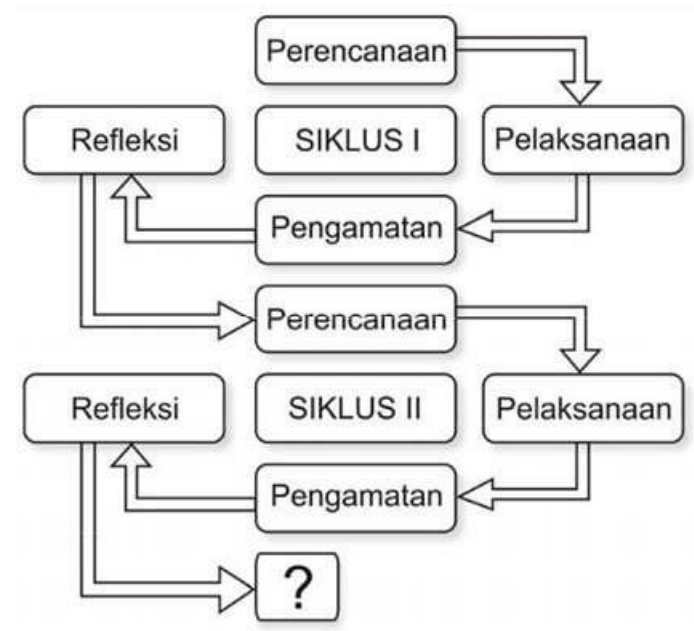

Gambar 1. Prosedur Pelaksanaan Penelitian Tindakan Kelas

\section{HASIL DAN PEMBAHASAN}

Penelitian ini dilaksanakan selama dua siklus dengan menerapkan lima langkah model pembelajaran Problem Based Learning yaitu: (1) orientasi masalah, (2) pengorganisasian siswa, (3) membimbing siswa untuk melakukan penyelidikan, (4) mengembangkan dan menyajikan hasil karya, (5) analisis dan evaluasi. Langkahlangkah yang dilakukan pada pembelajaran ini sudah sesuai dengan langkah-langkah PBL yang dikemukakan oleh Hardini dan Sari (2012: 18).

Hasil observasi penerapan PBL terhadap guru dan siswa mengalami peningkatan pada setiap siklusnya hingga mencapai indikator kinerja penelitian yang ditargetkan yaitu $85 \%$. Secara rinci, persentase hasil observasi guru dan siswa dari siklus I sampai siklus II dapat dilihat pada tabel 1. 
Tabel 1. Persentase Hasil Observasi Guru dan Siswa

\begin{tabular}{llcc}
\hline & & \multicolumn{2}{c}{ Siklus } \\
& & I & II \\
\hline Guru & Persentase (\%) & $85,41 \%$ & $90,78 \%$ \\
Siswa & Persentase (\%) & $81,04 \%$ & $87,94 \%$ \\
\hline
\end{tabular}

Persentase rata-rata hasil observasi guru pada siklus I adalah $85,41 \%$, dan pada siklus II meningkat menjadi $90,78 \%$. Persentase rata-rata hasil observasi siswa pada siklus I adalah $81,04 \%$, dan pada siklus II meningkat menjadi $87,94 \%$. Berdasarkan tabel 1 maka dapat disimpulkan bahwa setiap siklus mengalami peningkatan dan telah mencapai indikator kinerja, hal ini berarti model pembelajaran PBL dapat meningkatkan pembelajaran.

Pada langkah pertama model PBL, guru menjelaskan topik pembelajaran, tujuan pembelajaran yang akan dicapai, dan merumuskan masalah dengan cerita fenomena sehari-hari. Hal ini sesuai dengan pendapat Hosnan (2014: 301) yang menyatakan bahwa langkah orientasi masalah meliputi guru menyampaikan topik, tujuan pembelajaran dan sebagainya.

Pada langkah kedua, siswa diberikan pengumuman dan diberikan materi melalui grup whatsapp. Setelah itu guru membagi LKS kepada siswa. Langkah ini telah dilaksanakan oleh guru dan siswa.

Pada langkah ketiga, guru membimbing siswa untuk berdiskusi dan mengumpulkan informasi. Kegiatan ini sesuai dengan pendapat Hosnan (2014: 301) yang menyatakan bahwa pada langkah ini guru mendorong siswa untuk mengumpulkan informasi yang sesuai. Siswa mengumpulkan informasi dengan menggunakan media dan sumber lain seperti LKS dan video praktikum.

Pada langkah keempat, guru membimbing siswa untuk menyusun hasil percobaan, menuliskan hasil percobaaan pada LKS, mengarahkan siswa untuk mempresentasikan hasil percobaan, menyimpulkan hasil penyelidikan, menyimpulkan materi pembelajaran bersama siswa, serta siswa mengajukan pertanyaan ataupun tambahan saat pembelajaran. Langkah ini sesuai dengan pendapat Hosnan (2014: 300) yang menyatatkan bahwa karakteristik PBL siswa bertugas menyusun hasil penelitiannya dalam bentuk karya dan menyajikan hasil karyanya.

Pada langkah kelima, guru memberikan refleksi, memberikan kesempatan kepada siswa untuk menanyakan materi yang belum dipahami, membimbing siswa untuk mencatat hal-hal penting, melaksanakan kegiatan evaluasi, memberikan pesan moral. Kegiatan pada langkah kelima sesuai dengan pendapat Shoimin (2014: 131) yang menyatakan bahwa guru dan siswa melakukan refleksi dan evaluasi terhadap pembelajaran yang telah dilakukan.

Indikator kebehasilan pelaksanaan pembelajaran dengan menggunakan model pembelajara problem based learning tidak hanya diukur menggunakan hasil observasi yang dilakukan pada guru dan siswa, akan tetapi juga menggunakan hasil belajar siswa yang telah dilaksanakan menggunakan google formulir. Adapun hasil belajar IPA siswa kelas IVB SDN Dukuhan Kerten materi gaya setelah dilaksanakan model pembeljaran PBL dapat dilihat pada tabel 2.

Tabel 2. Hasil Belajar Siswa Siklus I dan II

\begin{tabular}{lcccc}
\hline \multirow{2}{*}{ Hasil Belajar } & \multicolumn{2}{c}{ Tuntas (\%) } & \multicolumn{2}{c}{ Belum Tuntas (\%) } \\
& Siklus I & Siklus II & Siklus I & Siklus II \\
\hline Pert 1 & 76 & 88 & 24 & 12 \\
Pert 2 & 80 & 92 & 20 & 8 \\
Rata-rata & 78 & 90 & 22 & 10 \\
\hline
\end{tabular}


Hasil belajar siswa kelas IV B materi gaya pada pada siklus I didapatkan hasil siswa tuntas sebesar $78 \%$ dan siswa belum tuntas sebesar $24 \%$, kemudian pada siklus II hasil belajar siswa yang tuntas meningkat menjadi $90 \%$ dan siswa belum tuntas $10 \%$. Berdasarkan hasil observasi dan wawancara, guru telah berhasil melaksanakan pembelajaran sesuai dengan langkah-langkah model pembelajaran PBL dan siswa telah mengikuti pembelajaran dengan baik.

Berdasarkan uraian hasil penelitian di atas, diketahui bahwa penerapan model pembelajaran PBL dapat meningkatkan pembelajaran dalam mata pelajaran IPA dilihat dari persentase ketercapaian target pada siklus I dan siklus II. Terjadinya peningkatan hasil belajar IPA dengan menerapkan PBL relevan dengan penelitian yang dilakukan oleh Nuraini dan Kristin (2017:11) yang menyatakan bahwa model Problem Based Learning dapat meningkatkan hasil belajar IPA. Hal ini diperkuat dengan penelitian Jayanti (2019:101) yang menyatakan bahwa model pembelajaran Problem Based Learning $(\mathrm{PBL})$ dapat meningkatkan hasil belajar IPA materi gaya.

Penelitian penerapan model PBL ini dilaksanakan selama 2 siklus dimana setiap siklus terdiri dari 2 pertemuan. Selama pelaksanaan penelitian, peneliti menjumpai beberapa kendala,yaitu: (1) masih ada siswa yang tidak memperhatikan pembelajaran dan asik bermain sendiri, (2) masih ada siswa yang belum aktif menanggapi apa yang disampaikan.

Kendala yang ada perlu diperbaiki. Adapun solusi dari kendala-kendala di atas, yaitu: (1) menegur dan menasehati siswa agar memperhatikan pembelajaran, (2) memberikan rangsangan siswa agar aktif menanggapi pembelajaran dengan cara memberi pertanyaan sesuai apa yang dipresentasikan. Melalui solusi tersebut, peneliti berharap kendala yang muncul dapat berkurang dan pembelajaran dapat berlangsung dengan baik.

\section{SIMPULAN}

Berdasarkan penelitian yang telah dilakukan, dapat disimpulkan bahwa penerapan model pembelajaran PBL dapat meningkatkan pembelajaran IPA tentang gaya pada siswa kelas IVB SD Negeri Dukuhan Kerten Tahun Ajaran 2020/2021. Persentase rata-rata hasil observasi guru pada siklus I sebesar $85,41 \%$ dan siklus II sebesar $90,78 \%$. Persentase rata-rata hasil observasi siswa pada siklus I sebesar $81,04 \%$ dan siklus II sebesar $87,94 \%$. Persentase hasil belajar siswa tuntas sebesar $78 \%$ pada siklus I dan $90 \%$ pada siklus II.

Peneliti mengajukan saran sebagai berikut: (1) penerapan model Problem Based Learning hendaknya dijadikan alternatif bagi guru untuk meningkatkan pembelajaran materi IPA, (2) sekolah hendaknya dapat melengkapi sarana dan prasarana penunjang proses pembelajaran, sehingga proses kegiatan belajar mengajar dapat berjalan dengan lancar, aktif, kreatif, dan bermakna bagi siswa, dan (3) bagi peneliti lain yang akan meneliti penerapan PBL, penelitian ini dapat dijadikan sebagai acuan atau referensi.

\section{DAFTAR PUSTAKA}

Arikunto, S. (2013). Prosedur Penelitian: Suatu Pendekatan Praktik. Jakarta: Rineka Cipta.

Hardini, dan Sari, P. 2012. Strategi Pembelajaran Terpadu (Teori, Konsep, \& Implementasi). Yogyakarta: Familia (Group Relasi Inti Media).

Hosnan, M. (2014). Pendekatan Saintifik dan Kontekstual dalam Pembelajaran abad 21 Kunci Sukses Implementasi Kurikulum 2013. Bogor: Ghalia Indonesia

Jayanti. (2019). Peningkatan Hasil Belajar IPA Materi Gaya Melalui Model Problem Based Learning (PBL) pada Siswa Kelas IV MI MA'ARIF Tingkir Lor Kota Salatiga Tahun Pelajaran 2018/2019. Skripsi 
Nuraini, F dan Kristin, F. (2017). Penggunaan model Problem Based Learning (PBL) untuk Meningkatkan Hasil Belajar IPA Siswa Kelas 5 SD. E-jurnal mitra pendidikan, 1 ( 4), 369-479.

Sani, R (2015). Pembelajaran Saintifik Untuk Implementasi Kurikulum 2013. Jakarta: Bumi Aksara.

Shoimin,A. (2014). 68 Model Pembelajaran Inovatif Dalam Kurikulum 2013. Yogyakarta : Ar-Ruzz Media

Uno, HB \& Muhammad, N. (2015). Belajar Dengan Pendekatan Pailkem. Jakarta: PT Bumi Aksara

Wisudawati \& Sulistyowati (2015). Metodologi Pembelajaran IPA. Jakarta: PT Bumi Aksara. 